\title{
Produção e autoconsumo de açaí pelos ribeirinhos do Município de Igarapé-Miri,
}

\section{Pará}

\author{
Production and self-consumption of açaí by riverside dwellers in the Municipality of Igarapé-Miri, \\ Pará
}

Producción y autoconsumo de açaí por pobladores ribreños del Municipio de Igarapé-Miri, Pará

Recebido: 18/07/2021 | Revisado: 23/07/2021 | Aceito: 24/07/2021 | Publicado: 01/08/2021

\author{
Hellem Pinheiro Almeida \\ ORCID: https://orcid.org/0000-0003-0653-2457 \\ Universidade do Estado do Pará, Brasil \\ E-mail: hellem.hpa@gmai.com \\ Alfredo Kingo Oyama Homma \\ ORCID: https://orcid.org/0000-0003-0330-9858 \\ Embrapa Amazônia Oriental, Brasil \\ Universidade do Estado do Pará, Brasil \\ E-mail: alfredo.homma@embrapa.br \\ Antônio Jose Elias Amorim de Menezes \\ ORCID: https://orcid.org/0000-0002-3294-5354 \\ Embrapa Amazônia Oriental, Brasil \\ E-mail: antonio.menezes@embrapa.br \\ Gisalda Carvalho Filgueiras \\ ORCID: https://orcid.org/0000-0002-4695-6505 \\ Universidade Federal do Pará, Brasil \\ E-mail: gisalda.filgueiras@gmail.com \\ João Tomé de Farias Neto \\ ORCID: https://orcid.org/0000-0002-0404-3556 \\ Embrapa Amazônia Oriental, Brasil \\ E-mail: joao.farias@embrapa.br
}

\begin{abstract}
Resumo
O açaízeiro é palmeira nativa da região amazônica, com ocorrência em solos de várzeas, igapó e terra firme. Foi efetuado o diagnóstico socioeconômico e a estimativa da produção e do autoconsumo dos produtores de açaí no município de Igarapé-Miri, Pará. Foram entrevistados 61 produtores ribeirinhos das comunidades Anapú, Caji e Meruú em julho e agosto de 2019. A renda média é de 1 a 2 salários mínimos mensais. As transferências governamentais mais recebidas pelos ribeirinhos são a Bolsa Família e aposentadoria. Observou-se que a produção de fruto por família foi de $36.139,98 \mathrm{~kg}$, sendo $22.238,61 \mathrm{~kg}$ na safra e $13.901,38 \mathrm{~kg}$ na entressfra. Vale ressaltar que o açaí consumido pelos ribeirinhos representa $16 \%$ da produção total, sendo $10 \%$ da safra e $6 \%$ da entressafra. No período da safra, os familiares consomem em média 7,46 litros de açaí grosso/dia, enquanto que na entressafra o consumo médio é de 8,07 litros de açaí fino/dia. A farinha de mandioca, peixe e alguns produtos industrializados compõe a dieta alimentar junto com o açaí.
\end{abstract}

Palavras-chave: Euterpe oleracea; Açaí; Produção; Autoconsumo; Safra; Entressafra.

\begin{abstract}
Açaí is a palm tree native to the Amazon region, occurring in lowland and highland areas. A socioeconomic survey and an estimate of the production and self-consumption of açaí producers in the municipality of Igarapé-Miri, in Pará, were carried out. In July and August 2019, 61 riverine producers from the Anapú, Caji and Meruú communities were interviewed. The average income is 1 to 2 minimum wages per month. The most governement transfers received by riverside dwellers are Bolsa Família and retirement. It was observed that the production of fruits per family was $36,139.98 \mathrm{~kg}$, being $22,238.61 \mathrm{~kg}$ in the harvest and $13,901.38 \mathrm{~kg}$ in the off-season. It is noteworthy that the açaí consumed by riverside dwellers represents $16 \%$ of total production, with $10 \%$ in the harvest and $6 \%$ in the off-season. During the harvest, family members consume an average of 7.46 liters of thick açaí/day, while in the off-season the average consumption is 8.07 liters of fine açaí/day. Cassava flour, fish and some industrialized products are part of the diet together with açaí.
\end{abstract}

Keywords: Euterpe oleracea; Açaí; Production; Self-consumption; Harvest and off season.

\section{Resumen}

El açaí es una palmera nativa de la región amazónica, que se encuentra en las tierras bajas y altas. Se realizó un diagnóstico socioeconómico y una estimación de la producción y autoconsumo de los productores de açaí en el 
municipio de Igarapé-Miri, en Pará. En julio y agosto de 2019 se entrevistaron a 61 productores ribereños de las comunidades Anapú, Caji y Meruú. El ingreso promedio es de 1 a 2 salarios mínimos por mes. Las transferencias gubernamentales que más reciben los habitantes de las riberas son Bolsa Família y jubilación. Se observó que la producción de frutos por familia fue de $36.139,98 \mathrm{~kg}$, siendo $22.238,61 \mathrm{~kg}$ en la cosecha y $13.901,38 \mathrm{~kg}$ en la temporada baja. Es de destacar que el açaí consumido por los ribereños representa el 16\% de la producción total, con un $10 \%$ en la cosecha y un $6 \%$ fuera de temporada. Durante la cosecha, los familiares consumen una media de 7,46 litros de açaí espeso/día, mientras que fuera de temporada el consumo medio es de 8,07 litros de açaí fino/día. Harina de yuca, pescado y algunos productos industrializados forman parte de la dieta junto con el açaí.

Palabras clave: Euterpe oleracea; Açaí; Producción; Autoconsumo; Cosecha fuera de temporada.

\section{Introdução}

O açaizeiro (Euterpe oleracea Mart.) é uma palmeira característica da Amazônia que possui importância econômica e social. Segundo Santana (2017), o habitat natural da espécie são as regiões de várzea, entretanto pode desenvolver-se em matas de terra firme e ocorre espontaneamente no Brasil, sendo a Amazônia, a região que concentra o gênero Euterpe com destaque para os estados do Pará, Amapá, Maranhão, Tocantins e Mato Grosso. Considerada um dos principais produtos extrativos vegetais da floresta amazônica utilizado na alimentação da população regional, consumida na forma de bebidas, doces, geleias e sorvetes, bem como fornecedor de frutos para exportação (nacional e externa) e, por constituir na fonte de matéria-prima da agroindústria de palmito em conserva (Azevedo, 2005).

Antes do surgimento de indústrias de beneficiamento, os açaizais tinham uma produção extrativista em que os frutos de açaí eram destinados para a subsistência das famílias ribeirinhas. A comercialização de excedente era ínfima em associação e os ribeirinhos se dedicavam ao cultivo do arroz (Oryza sativa L.), mandioca (Manihot esculenta Crantz), além da coleta de peixes, camarões e, o cultivo de cana-de-açúcar (Saccharum officinarum L.) para fabricação de aguardente (Homma et al, 2006).

A partir da década de 1960 acentou no estuário amazônico a extração do palmito destinada para exportação (interna e externa) praticado pelos ribeirinhos, enquanto que os frutos eram voltados para a alimentação das famílias ribeirinhas, assim como para o mercado local (Nogueira \& Homma, 1998). Para os produtores do estuário amazônico, o açaí era considerado o alimento basilar, e depois da década de 1990, conquistou novos mercados de consumo, ganhando notoriedade no cenário nacional e internacional, em virtude das suas inúmeras propriedades (Rojas, 2017). Com o aumento da demanda nos mercados local, nacional e internacional, bem como a crescente popularidade, o mesmo é denominado de "superfruta", pois o seu consumo está aumentando significativamente devido ao seu sabor único e das propriedades nutricionais, tais como: alta energia, antioxidante, anti-inflamatório e cardioprotetor (Yamaguchi et al., 2015).

De acordo com Mendes et al. (2012), o açaí é uma das fruteiras nativas mais significativas do Estado do Pará, uma vez que responde por $70 \%$ da renda dos ribeirinhos. Vale ressaltar que o fruto é consumido pela população da Amazônia desde a era pré-colombiana, pelos indígenas que habitavam a região do estuário (Mourão, 2010). Nos estados do Pará e Amapá, a polpa e o palmito são tradicionalmente consumidos na região e auxiliam na sobrevivência da população ribeirinha (Silva, 2018).

O fruto consumido como polpa obtido pela maceração do fruto (pericarpo) com diferentes quantidades de água de forma manual, mecânica pelos "batedores" e pelas indústrias de beneficiamento apresenta diversidade significativa de produtos alimentícios (sorvetes, licores, doces, néctares e geleias), cosméticos e energéticos e aproveitamento de caroços e palha (Vieira et al., 2018). Desse modo, o açaí que era consumido dentro do contexto da cultura local, acompanhado com farinha de mandioca, peixe frito ou assado, camarão salgado tornou-se alimento básico, com notoriedade e amplitude significativa no mercado regional, nacional e internacional. Conforme Freddo (2018), o açaí possui sabor que agrada bastante a população 
amazônica, podendo ser consumido na forma de polpa, com farinha de mandioca ou tapioca e açúcar, e com camarão ou peixe salgado, hábito trivial entre os paraenses.

Um dos principais usos do açaí é o consumo da polpa, que nos últimos anos passou a ser utilizado também como bebida energética e nutracêutica em outras regiões do País, aumentando a demanda sobre esse produto amazônico. No Estado do Pará, a região do Baixo Tocantins, destaca-se com uma significativa produção e extração do fruto. Nesse contexto, o município de Igarapé-Miri é um dos maiores produtores e exportadores do fruto, não obstante, os produtores além de possuírem renda gerada a partir da produção do fruto, também, utilizam-o como alimento essencial da dieta alimentar.

Verifica-se um aumento considerável de estudos sobre o açaí, assim como a comercialização, no entanto, tem-se carência de dados sobre a produção e o autoconsumo pelas famílias produtoras, uma vez que dados secundários obtidos não registram o açaí consumido pelas famílias ribeirinhas. Esta subestimação da produção dificulta as projeções para o mercado e a inserção de políticas públicas para fomento (Guedes, 2018). Em virtude da escassez de informações sobre o autoconsumo de açaí pelos produtores do fruto, o presente estudo estimou a produção e o autoconsumo de açaí pelos ribeirinhos do município de Igarapé-Miri.

\section{Materiais e Método}

\section{1 Área de estudo}

A pesquisa foi realizada no município de Igarapé-Miri, localizado na mesorregião do Nordeste Paraense (Baixo Tocantins), a uma latitude $01^{\circ} 58^{\prime} 30^{\prime \prime}$ sul e a uma longitude $48^{\circ} 57^{\prime} 35^{\prime \prime}$ oeste, estando a uma altitude de 17 metros. Limita-se ao Norte com o município de Abaetetuba; a Leste com Moju; ao Sul com Cametá e Moju e a Oeste com Cametá e Limoeiro do Ajurú (Idesp, 2011).

Apresenta uma extensão territorial de, aproximadamente, 1.996,790 km², à 78 km de Belém, capital do estado, com população estimada em 62.698 habitantes, perfazendo uma densidade demográfica de 29,08 hab/km² (Ibge 2019). O território é composto por áreas de várzea (ilhas) e terras firmes, caracterizada por uma extensa relação da população com o meio natural (Silva, 2017). 
Figura 1: Localização do município de Igarapé-Miri e os locais entrevistados.

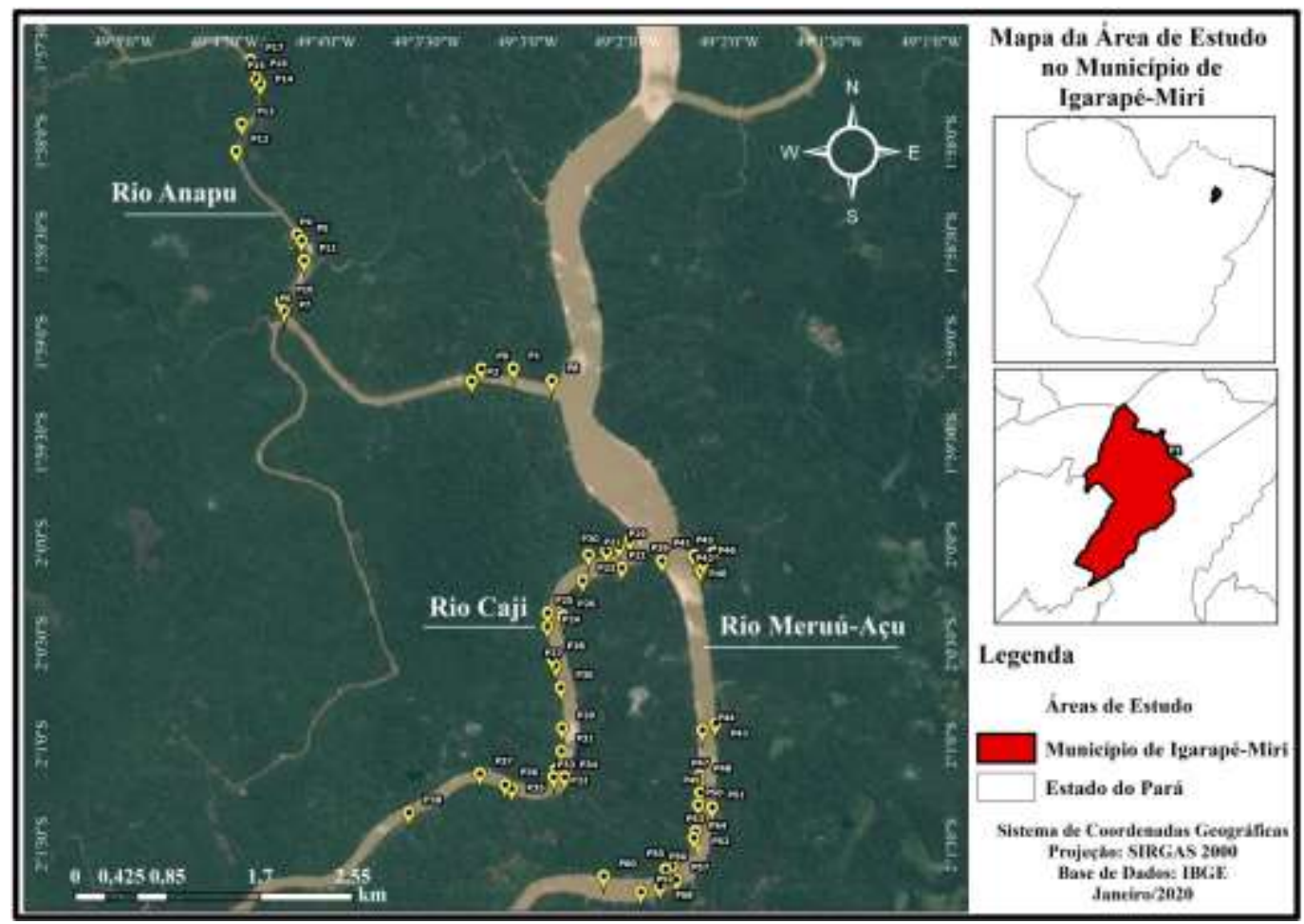

Fonte: Dados da pesquisa (2019)

$\mathrm{O}$ estudo foi conduzido com produtores de açaí correspondente a três comunidades rurais de Igarapé-Miri: Anapú ( $\mathrm{S}$

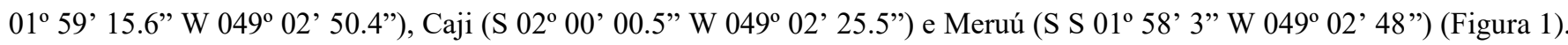
Cada comunidade foi selecionada levando em consideração a representatividade na produção de açaí do município, e ainda, pelo fato estarem mais afastadas do centro urbano e possuírem maior núcleo populacional. $\mathrm{O}$ acesso, às referidas comunidades é, por via fluvial, com um tempo de percurso de, em média, 1:30 à 2:00 horas para se chegar até as comunidades estudadas e o deslocamento dar-se por meio de embarcações de médio e pequeno porte.

\subsection{Sujeitos da pesquisa e procedimentos de amostragem}

Previamente, ao início da coleta de dados, a pesquisa foi submetida ao Comitê de Ética em Pesquisa (CEP) da Universidade do Estado do Pará (UEPA), com o Certificado de Apresentação para Apreciação Ética (CAAE) sob o número 21213019.9.0000.5174, sendo aprovado com o Parecer 3.717.199.

Foi realizado contato com o Sindicato dos Produtores Rurais de Igarapé-Miri, a Secretaria de Estado de Meio Ambiente e Sustentabilidade de Igarapé-Miri e os líderes comunitários dos produtores de açaí. O objetivo das visitas pilotos e reuniões informais com as lideranças locais e informantes-chave foi expor a finalidade do trabalho, selecionar as comunidades rurais mais indicadas para a realização do estudo, conforme o objetivo pretendido, além de solicitar a autorização e participação dos produtores de açaí no desenvolvimento da pesquisa.

Com a seleção e concordância dos produtores para participação na pesquisa, aplicou-se um questionário teste, com o intuito asseverar as perguntas e assim realizar as modificações necessárias para a realização das entrevistas nas três comunidades estudadas.

A pesquisa apresenta abordagem quanti-qualitativa. Menezes et al (2019), mostra que a abordagem qualitativa investiga a apreensão de um fenômeno em profundidade, tendo o ambiente natural como a fonte direta dos dados e o 
pesquisador como instrumento-chave. Além de supor o contato direto e prolongado do pesquisador com o ambiente e a situação que está sendo investigada, via de regra, por meio do trabalho intensivo de campo. A abordagem quantitativa, busca a validação das hipóteses mediante a utilização de dados estruturados. A utilização conjunta da pesquisa qualitativa e quantitativa permite recolher mais informações do que se poderia conseguir isoladamente (Lakatos, Marconi, 2004). Logo, a pesquisa qualitativa foi utilizada para obter o aprofundamento das informações sobre a produção do açaí em Igarapé-Miri e sua relação com o consumo de açaí pelos produtores do fruto. E a abordagem quantitativa foi usada para generalizar os resultados.

Quanto aos procedimentos, caracteriza-se como uma pesquisa bibliográfica (levantamento de referências teóricas já analisadas e publicadas) e como pesquisa de campo (investigações em que se realiza coleta de dados junto a indivíduos) (Gerhardt, 2009).

\subsection{Amostra e coleta de dados}

O levantamento de campo foi realizado no período de 23 de julho a 9 de agosto de 2019, nas comunidades Anapú; Caji e Meruú. Para tanto, foram realizadas entrevistas com a aplicação de 61 questionários semiestruturados aos produtores de açaí, sendo 17 questionários aplicados na comunidade ribeirinha de Anapú, 21 em Caji e 23 no Meruú das referidas comunidades rurais do município de Igarapé-Miri.

A seleção dos ribeirinhos contou com o auxílio de lideranças locais dentro de cada comunidade, com o intuito de indicar produtores com o perfil de interesse do estudo. Para a realização da pesquisa de campo, decidiu-se por uma amostragem intencional ou julgamento, considerando os maiores produtores de cada comunidade, bem como aqueles que fornecem o fruto para outras localidades, como Belém e Castanhal. De acordo Lakatos e Marconi (2010), a amostra intencional é a mais comum entre as não-probabilísticas e consiste na escolha dos elementos da amostra por um especialista no assunto, que seleciona os elementos que julga os mais apropriados e representativos para o estudo em questão. Além da caminhada transversal que consiste em percorrer uma determinada área, acompanhado de informantes locais e que conheçam bastante a região (Rocha et al., 2015). Após a coleta de dados, os mesmos foram submetidos a tratamentos estatísticos por meio dos software Excell 2010.

\section{Resultados e Discussão}

Com base na pesquisa realizada foram analisados os dados que refletissem o perfil de produção e autoconsumo de açaí pelos ribeirinhos.

\subsection{Consumo de açaí pelos produtores de açaí}

A maioria das famílias dos produtores de açaí é constituída por 1 a 18 pessoas, sendo que 70,49\% são formadas por até 5 membros, 6 a 10 pessoas constituem 27,87\% e 1,64\% com 11 a 18 moradores. O número total de membros familiares é 285 e a média dos membros é 5 (Tabela 1). Silva et al (2016), observaram que a maioria das residências registrou uma quantidade de 3 a 5 moradores, considerado baixo para os padrões ribeirinhos que advêm de poucos recursos contraceptivos acarretando em famílias numerosas. 
Tabela 1 - Composição familiar das comunidades Anapú, Meruú e Caji.

\begin{tabular}{llll}
\hline Composição Familiar & Número de Produtores & $\%$ & Média \\
\hline 1 a 5 & 43 & 70,49 & 3,14 \\
6 a 10 & 17 & 27,87 & 7,76 \\
11 a 18 & 1 & 1,64 & 18,00 \\
\hline TOTAL & $\mathbf{6 1}$ & $\mathbf{1 0 0 , 0 0}$ & $\mathbf{4 , 6 7}$ \\
\hline
\end{tabular}

Fonte: Dados da pesquisa (2019).

Dos 61 entrevistados nas comunidades de Anapú, Caji e Meruú, verificou-se que quase a totalidade dos ribeirinhos (98,36\%) consomem açaí e apenas 1,64\% não consome (Figura 2), por razões de saúde, devido acreditar não ser recomendado para diabetes e doenças cardiovasculares. No entanto, pesquisas revelam que o açaí, por apresentar em sua composição quantidades significativas de flavonoides (antocianinas), destaca-se no controle e/ou prevenção de algumas doenças (diabetes, dislipidemia e doença cardiovascular), pois além de demonstrar alta capacidade antioxidante, apresenta benefícios nutricionais e terapêuticos como, por exemplo, ação antiproliferativa; anti-inflamatória e efeito cardioprotetor (Cedrim et al., 2018).

O consumo de açaí pela família rural é essencial e compõe mais da metade da ingestão calórica. Nas mesas rurais, o acompanhamento pode incluir farinha de mandioca, camarão, peixe e arroz, mas a ausência do açaí contribui para o cardápio ser considerado uma refeição incompleta (Pepper; Alves, 2016).

Figura 2 - Consumo de açaí pelos ribeirinhos das comunidades Anapú, Meruú e Caji.

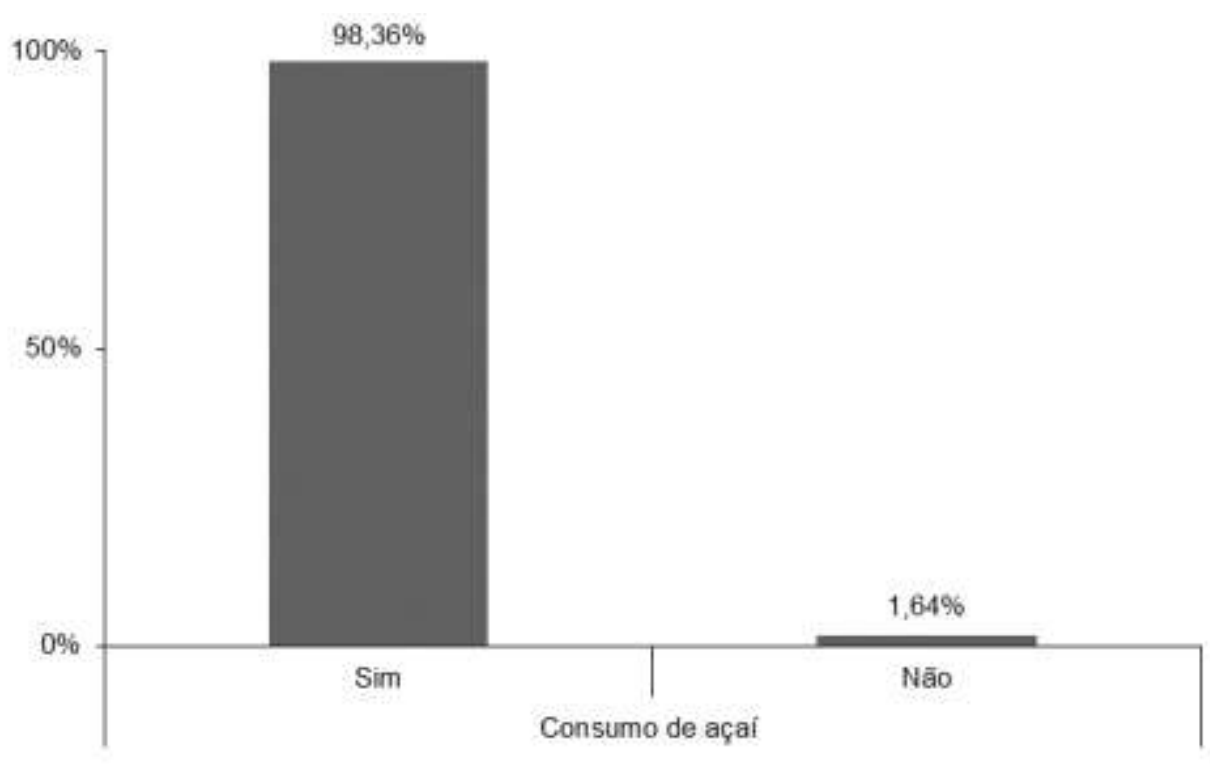

Fonte: Dados da pesquisa (2019).

O consumo de açaí na região do estuário ocorre há vários séculos, pois era elemento primordial na alimentação indígena, sendo considerado o segundo produto mais consumido do estuário amazônico, além de auxiliar na sobrevivência da população ribeirinha (Silva et al, 2016). 


\subsection{Tipo de açaí preferido}

O açaí é um alimento essencial na dieta alimentar dos ribeirinhos, existindo dois tipos encontrados que são: açaí preto e branco. A maioria dos produtores desse fruto (70,49\%), apresenta preferência pelo preto, enquanto que $19,67 \%$ dos entrevistados gostam mais de consumir o branco. Cerca de 9,84\% dos produtores responderam que tanto faz o tipo, pois consomem as duas variedades, não tendo, portanto, preferência revelada (Figura 3). É importante ressaltar que a preferência do açaí preto em detrimento do branco não está relacionada com a escassez do branco, pois mesmo em menor quantidade, o pouco que fica disponível não é consumido, chegando até a secar na palmeira, por falta de valorização pelos ribeirinhos locais, explicado, talvez, pela questão cultural.

Figura 3 - Consumo de açaí preto e branco pelos ribeirinhos das comunidades Anapú, Meruú e Caji.

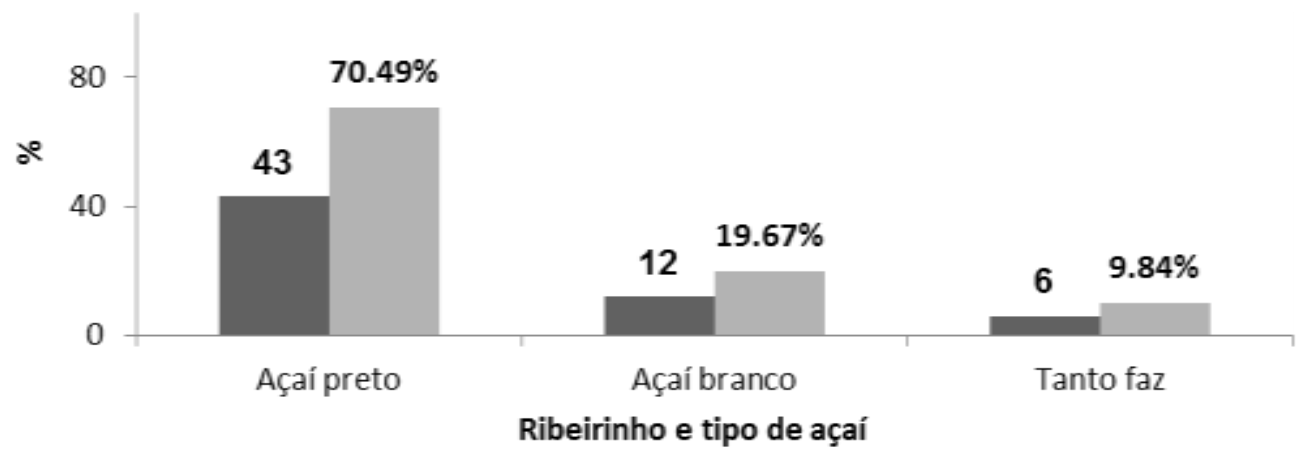

Fonte: Dados da pesquisa (2019).

Com relação ao consumo de farinha em associação com açaí, verifica-se que todos os entrevistados, relataram o consumo da polpa associado com farinha. O tipo de farinha mais frequente nas refeições é a farinha d'água, com 72,13\%, que consiste no produto das raízes de mandioca que são fermentadas em água, separadas das cascas, prensadas e torradas (Silva, 2013). Tanto a farinha de mandioca (d'água) quanto a farinha de tapioca (produzida a partir da fécula da mandioca) são consumidas por $26,23 \%$ dos produtores. A minoria dos entrevistados (1.64\%), mencionou que além do consumo de farinha d'água e tapioca, também, utilizam aveia no consumo de açaí (Tabela 2). De acordo com Silva (2014), farinha de mandioca é o principal complemento na alimentação e fonte de energia de origem não-animal da dieta local.

Tabela 2 - Consumo de açaí com farinha e tipo de farinha utilizada nas comunidades Anapú, Meruú e Caji.

\begin{tabular}{lll}
\hline Consumo de Açaí com Farinha & Número de Produtores & $\mathbf{\%}$ \\
\hline Sim & 61 & 100 \\
Não & 0 & 0 \\
\hline Total & $\mathbf{6 1}$ & $\mathbf{1 0 0 , 0 0}$ \\
\hline Tipo de Farinha & Número de Produtores & $\%$ \\
\hline Farinha mandioca (d'água) & 44 & 72,13 \\
Farinha mandioca (d'água) e farinha tapioca & 16 & 26,23 \\
Farinha mandioca (d'água), farinha tapioca e tapioca+aveia & 1 & 1,64 \\
\hline Total & $\mathbf{6 1}$ & $\mathbf{1 0 0 , 0 0}$ \\
\hline
\end{tabular}

Fonte: Dados da pesquisa (2019). 
No que se refere ao consumo de açaí com açúcar, cerca de 86,89\% dos produtores do fruto não consomem açaí com açúcar e 13,11\% adicionam açúcar na polpa (Tabela 3). Essa minoria, relata que o hábito foi adquirido devido à influência de parentes que residem na área urbana do município (cidade de Igarapé-Miri) e/ou Belém.

Tabela 3 - Consumo de açaí com açúcar nas comunidades Anapú, Meruú e Caji.

\begin{tabular}{lll}
\hline Consumo de Açaí com Açúcar & Número de Produtores & \% \\
\hline Sim & 8 & 13,11 \\
Não & 53 & 86,89 \\
\hline Total & $\mathbf{6 1}$ & $\mathbf{1 0 0 , 0 0}$ \\
\hline
\end{tabular}

Fonte: Dados da pesquisa (2019).

\subsection{Frequência e consumo diário de açaí}

No que tange ao consumo de açaí, percebe-se que $96,72 \%$ dos entrevistados consomem polpa todos os dias da semana, enquanto que 3,28\% afirmaram não ingerir diariamente (Tabela 4). Observa-se que o açaí não é somente fonte de renda e melhoria de qualidade de vida dos ribeirinhos, mas também compõe a dieta alimentar dos produtores, pois é muito difícil eles não consumirem açaí nas refeições, e às vezes, somente o consumo da polpa já é o suficiente para ficarem satisfeitos.

Tabela 4 - Consumo diário de açaí, frequência de consumo e refeição com maior consumo nas comunidades Anapú, Meruú e Caji.

\begin{tabular}{lll}
\hline Consumo Diário & Produtores & $\mathbf{\%}$ \\
\hline Sim & 59 & 96,72 \\
Não & 2 & 3,28 \\
\hline Total & $\mathbf{6 1}$ & $\mathbf{1 0 0 , 0 0}$ \\
\hline Frequência de Consumo & Produtores & $\mathbf{\%}$ \\
\hline Almoço, jantar e merenda & 55 & 90,16 \\
Almoço e jantar & 4 & 6,56 \\
Almoço e merenda & 2 & 3,28 \\
\hline TOTAL & $\mathbf{6 1}$ & $\mathbf{1 0 0 , 0 0}$ \\
\hline Refeição com maior Consumo & Produtores & $\mathbf{\%}$ \\
\hline Almoço & 12 & 19,67 \\
Jantar & 4 & 6,56 \\
Almoço e jantar & 45 & 73,77 \\
\hline Total & $\mathbf{6 1}$ & $\mathbf{1 0 0 , 0 0}$ \\
\hline
\end{tabular}

Fonte: Dados da pesquisa (2019).

Quanto a frequência de consumo, verifica-se que $90,16 \%$ dos produtores consomem a polpa no almoço, merenda e jantar. Ao passo que 6,56\% ingerem açaí no almoço e jantar, e somente, 3,28\% consomem no almoço e merenda (Tabela 4). De acordo com os dados coletados, observa-se que a maior frequência de consumo de açaí é no almoço, merenda e jantar, devido à ingestão da polpa ser hábito alimentar indispensável para os produtores, sendo consumido não apenas nas refeições tradicionais (almoço e jantar), mas também na merenda, uma vez que o açaí é adicionado no mingau de arroz ou farinha, 
consumido pelos ribeirinhos; seus familiares e trabalhadores geralmente pela manhã, às nove horas, como merenda com o intuito de ser um alimento que forneça energia necessária para a realização das atividades até o almoço.

A refeição com maior consumo de açaí são almoço e jantar, com o equivalente à $73,77 \%$, o almoço é a refeição de segundo maior consumo da polpa com 19,67\% e o jantar é o terceiro com 6,56\% (Tabela 4). Embora no jantar tenha-se o menor índice de consumo entre as demais refeições diárias, muitos produtores optam por consumir uma maior quantidade de polpa, nessa refeição, devido ser um alimento que fornece sensação de saciedade e essa percepção é acentuada e se for consumida muita polpa no almoço, afeta a execução das atividades posteriores.

\subsection{Consumo de açaí na safra e entressafra}

Baseado no levantamento realizado, verifica-se que os ribeirinhos consomem açaí tanto no período da safra quanto na entressafra. Desse modo, as Tabelas 5 e 6 mostram os dados relativos ao consumo do açaí pelos produtores. No consumo familiar estão incluídos trabalhadores avulsos que participam na coleta do fruto e que não foi possível desagregar do total da polpa que foi preparado para este segmento.

Tabela 5 - Consumo diário de açaí no período da safra pelos ribeirinhos das comunidades Anapú, Caji e Meruú.

\begin{tabular}{llll}
\hline Litros (L) & Produtores & \% & Média (L) \\
\hline 1 a 4 & 11 & 18,03 & 2,73 \\
4,1 a 8 & 34 & 55,74 & 6,44 \\
8,1 a 13 & 11 & 18,03 & 10,55 \\
13,1 a 17 & 2 & 3,28 & 15,00 \\
17,1 a 21 & 3 & 4,92 & 20,00 \\
\hline Total & $\mathbf{6 1}$ & $\mathbf{1 0 0 , 0 0}$ & $\mathbf{7 , 4 6}$ \\
\hline
\end{tabular}

Fonte: Dados da pesquisa (2019).

Durante o período da safra, 4,92\% dos ribeirinhos, consome até 21 litros de polpa por dia por família. A maioria $(55,74 \%)$ ingere de 4,1 a 8 litros diariamente por família. Enquanto que a minoria dos entrevistados (3,28\%), consome 13,1 a 17 litros por dia por família.

A Tabela 6 revela o consumo da polpa no período da entressafra. Percebe-se que os ribeirinhos chegam a consumir até 25 litros de polpa $(1,64 \%)$ por família, sendo que essa polpa é considerada muito fina, ou seja, o consumo de açaí não diminui nesse período, mesmo com menor disponibilidade (ou mesmo não tendo). 
Tabela 6 - Consumo de açaí no período da entressafra pelos ribeirinhos das comunidades Anapú, Caji e Meruú.

\begin{tabular}{lll}
\hline Litros (L) & Produtores & $\%$ \\
\hline 0 & 1 & 1,64 \\
1 a 4 & 16 & 26,23 \\
4,1 a 8 & 25 & 40,98 \\
8,1 a 13 & 8 & 13,11 \\
13,1 a 17 & 5 & 8,20 \\
17,1 a 21 & 5 & 8,20 \\
21,1 a 25 & 1 & 1,64 \\
\hline Total & $\mathbf{6 1}$ & $\mathbf{1 0 0 , 0 0}$ \\
\hline
\end{tabular}

Fonte: Dados da pesquisa (2019).

A quantidade de litros mais consumida é de 4,1 a 8 litros com 40,98\%, seguido de 1 a 4 litros (26,23\%) por família. Vale ressaltar que $1,64 \%$ dos entrevistados não consomem açaí no período da entressafra, devido não gostarem de açaí muito fino (em razão da diminuição da oferta do fruto), além de alguns membros da família não ingerir por questões de saúde, por acreditarem não ser recomendados para diabetes e hipertensão (Tabela 6).

A Tabela 7, tem-se o consumo per capita por dia e anual da polpa efetivada pelos ribeirinhos. Quanto ao autoconsumo, verificou-se que na safra os produtores apresentam 1,60 litro de consumo per capita diário e 292,80 litros per capita familiar safra. Na entressafra, o consumo per capita familiar por dia é 1,73 litro e durante toda a entressafra é de 314,86 litros. Sendo assim, o consumo familiar per capita anual de polpa pelos produtores do fruto tanto na safra quanto na entressafra equivale a 607,66 litros, refletindo a intensa relação de consumo do ribeirinho com este recurso.

Tabela 7 - Consumo per capita de açaí na safra e entressafra pelos ribeirinhos das comunidades Anapú, Caji e Meruú.

\begin{tabular}{|c|c|c|c|c|}
\hline Safra & & Entressafra & & Safra e Entressafra \\
\hline $\begin{array}{l}\text { Consumo per } \\
\text { capita por dia } \\
\text { (L/dia) }\end{array}$ & $\begin{array}{l}\text { Consumo per } \\
\text { capita na safra } \\
\text { (L) }\end{array}$ & $\begin{array}{l}\text { Consumo per } \\
\text { capita por dia } \\
\text { (L/dia) }\end{array}$ & $\begin{array}{l}\text { Consumo per } \\
\text { capita } \\
\text { entressafra (L) }\end{array}$ & $\begin{array}{l}\text { Consumo per capita anual (Safra } \\
\text { e Entressafra L/Ano) }\end{array}$ \\
\hline 1,60 & 292,80 & 1,73 & 314,86 & 607,66 \\
\hline
\end{tabular}

Fonte: Dados da pesquisa (2019).

Na safra é consumido, em média, 7,46 litros por família e na entressafra 8,07 litros por família, sendo que a média da composição familiar corresponde a 5 membros que consomem açaí na merenda, almoço e jantar. Vale ressaltar que na entressafra, mesmo tendo uma menor oferta do fruto, os produtores deixam de vender para destinar a polpa para as refeições, devido ser item indispensável na dieta alimentar desses produtores e por ter menor disponibilidade do fruto, adiciona-se mais água com o intuito de obter maior rendimento, no entanto uma polpa muito fina, mas o que explica o maior consumo em litros do açaí nessa época.

De acordo com Bezerra (2016), consumidores do Estado do Pará com renda entre 2 a 4 salários mínimos apresentam consumo familiar anual de 102,1 litros de açaí. Contextualizando esses valores com outros produtos no Brasil, verifica-se que o consumo per capita de leite, em 2017, alcançou 166,7 litros/habitante, embora o consumo aparente per capita diminuir mais de 4 litros/habitante ao ano, devido ao crescimento da população associado à redução da disponibilidade interna de leite (Carvalho, 2018). O consumo de lácteos per capita no Brasil é de 173 litros; na Argentina, 200 litros; no Uruguai, 239 litros. O 
consumo de leite UHT apresentou crescimento, atingindo 7,026 bilhões de litros (Embrapa, 2018). Em 2018, o consumo de lácteos apresentou variação negativa, caindo de 166 para 165 litros/hab/ano, enquanto o leite UHT rompeu sua tendência anual de crescimento pela primeira vez, em dez anos, recuando 145 milhões de litros em 2018 em relação a 2017. Logo, o consumo aparente per capita, em 2018, foi de 165 litros/habitante (Embrapa, 2019).

Para Silva et al (2014), observou em seu estudo que o consumo diário de proteína animal apresentou o valor per capita entre 300 e 400g diários, sendo similar ao relatado por populações ribeirinhas de Monte Alegre (PA), que consomem diariamente $369 \mathrm{~g}$.

\subsection{Classificação do açaí consumido na safra e entressafra}

Tanto no período da safra quanto no da entressafra, o consumo de açaí pelas comunidades ribeirinhas (Anapú, Caji e Meruú) é contínuo, no entanto a classificação da polpa ingerida sofre alterações, como visualiza na Tabela 8. Quanto a classificação do açaí consumido, na safra, as categorias variam de grosso, médio, médio à grosso e fino. A maioria dos produtores (78,69\%) preferem açaí do tipo grosso e, apenas 1,64\% gostam de açaí fino. Vale ressaltar que, 16,39\% dos entrevistados, possuem preferência por açaí médio, mesmo sendo em período em que se tenha maior oferta do produto e consequentemente maior condição do açaí ser mais consistente (grosso).

Tabela 8 - Classificação do açaí consumido na safra e entressafra nas comunidades Anapú, Meruú e Caji.

\begin{tabular}{|c|c|c|c|c|c|}
\hline \multicolumn{3}{|l|}{ Safra } & \multicolumn{3}{|l|}{ Entressafra } \\
\hline $\begin{array}{l}\text { Classificação do } \\
\text { açaí }\end{array}$ & Produtores & $\%$ & $\begin{array}{l}\text { Classificação do } \\
\text { açaí }\end{array}$ & Produtores & $\%$ \\
\hline Grosso & 48 & 78,69 & Grosso & 3 & 4,92 \\
\hline Médio & 10 & 16,39 & Médio & 8 & 13,11 \\
\hline Médio à Grosso & 2 & 3,28 & Fino & 47 & 77,05 \\
\hline Fino & 1 & 1,64 & Muito Fino & 2 & 3,28 \\
\hline- & - & - & Não consome & 1 & 1,64 \\
\hline Total & 61 & 100,00 & & 61 & $\begin{array}{l}1100, \\
00\end{array}$ \\
\hline
\end{tabular}

Fonte: Dados da pesquisa (2019).

Verifica-se que na entressafra, a polpa do açaí, é classificada como grosso, médio, fino e muito fino. Diferentemente da safra, no período de menor oferta de açaí, o açaí classificado como fino é o que apresenta maior consumo (77,05\%), enquanto que somente $4,92 \%$ dos entrevistados consomem açaí grosso nessa época. É importante salientar que, em razão da menor oferta do açaí, 1,64\% dos entrevistados não consome nenhum tipo de açaí.

O regulamento técnico para fixação dos padrões de identidade e qualidade para polpa de açaí, estabelece uma classificação baseada na adição ou não de água e seus quantitativos, tais como: Açaí grosso ou especial (tipo A) é a polpa que apresenta acima de 14\% de sólidos totais e uma aparência muito densa. Açaí médio ou regular (tipo B) é quando possui acima de 11 a 14\% de sólidos totais e uma aparência densa. Açaí fino ou popular (tipo C) é quando apresenta de 8 a 11\% de sólidos totais e uma aparência pouco densa (Brasil, 2016). 


\subsection{Comportamento alimentar do consumo de açaí}

A principal forma de consumo de açaí entre os produtores é a associação do açaí com o alimento principal em conjunto com proteína animal e como sobremesa com percentual considerável 62,30\%, uma vez que os mesmos consomem, ao mesmo tempo, açaí com o alimento (refeição principal), além da ingestão do açaí na forma de sobremesa. A minoria dos entrevistados (37,70\%), afirmam consumir o açaí somente com alimento principal, dispensando a utilização do açaí na preparação de sobremesas (Tabela 9).

Tabela 9 - Modo de consumo de açaí e Tipos de sobremesas feitas com açaí nas comunidades Anapú, Caji e Meruú.

\begin{tabular}{lll}
\hline Modo de consumo de açaí & Produtores & $\mathbf{\%}$ \\
\hline Alimento principal junto com proteína & 23 & 37,70 \\
Alimento principal junto com proteína e como sobremesa & 38 & 62,30 \\
\hline Total & $\mathbf{6 1}$ & $\mathbf{1 0 0 , 0 0}$ \\
\hline Tipos de sobremesa de açaí & Produtores & $\mathbf{\%}$ \\
\hline Mingau de açaí & 58 & 92,11 \\
Chope & 1 & 2,63 \\
Picolé & 1 & 2,63 \\
Sorvete & 1 & 2,63 \\
\hline Total & $\mathbf{6 1}$ & $\mathbf{1 0 0 , 0 0}$ \\
\hline
\end{tabular}

Fonte: Dados da pesquisa (2019).

O açai, entre os ribeirinhos, não é usado apenas como polpa, mas, também, na fabricação de sobremesas, tais como: mingau de açaí, sorvete, picolé e chope. O mingau de açaí (92,11\%), seja de arroz ou farinha, é a sobremesa mais consumida, uma vez que é feito no período da manhã, sendo utilizado como merenda (Tabela 9), sendo, inclusive, comercializado nas ruas pela manhã. Segundo Nogueira et al (2005), com o açaí são produzidos sorvetes, licores, doces, néctares e geléias, bem como pode ser utilizado para a extração de corantes e antocianina.

\subsection{Alimentos consumidos em associação com o açaí}

A dieta alimentar, como já destacado anteriormente, dos ribeirinhos, é composta por comidas que são ingeridas em associação com o açaí. Os principais alimentos que compõem a dieta alimentar são peixe, camarão, charque, carne bovina, frango e porco representando $83,61 \%$ dos entrevistados. Além dos produtos básicos, tem-se o consumo de alimentos industrializados (mortadela, sardinha, conserva, salsicha etc.) com o equivalente a 1,64\% dos entrevistados. Verifica-se que $4,92 \%$ dos entrevistados relataram o consumo de sopa com farinha junto com o açaí e 1,64\% dos produtores afirmaram comerem banana como acompanhamento do açaí (Tabela 10). 
Tabela 10 - Alimentos consumidos em associação ao açaí nas comunidades Anapú, Caji e Meruú.

\begin{tabular}{|c|c|c|}
\hline Alimento Consumido Junto com Açaí & Produtores & $\%$ \\
\hline Peixe, camarão, charque, carne bovina, frango e porco & 51 & 83,61 \\
\hline $\begin{array}{l}\text { Peixe, camarão, charque, carne bovina, frango, porco e mortadela (produtos } \\
\text { industrializados) }\end{array}$ & 6 & 9,84 \\
\hline Banana & 1 & 1,64 \\
\hline Peixe, camarão, charque, carne bovina, frango, porco, sopa junto com farinha & 3 & 4,92 \\
\hline Total & 61 & $\mathbf{1 0 0 , 0 0}$ \\
\hline
\end{tabular}

Fonte: Dados da pesquisa (2019).

O açaí é usualmente consumido com farinha de mandioca, combinado com peixe, camarão ou carne, sendo o alimento básico para as populações de origem ribeirinha (Nogueira et al, 2005). De acordo com Santana (2014), o peixe e a farinha são considerados os principais alimentos complementares no consumo de açaí, principalmente, pelas comunidades de menor poder aquisitivo. A mistura de açaí com camarão, charque ou farinha de tapioca, devido ao preço elevado, expressam menor consumo. Para Silva et al (2014) o peixe é a principal fonte de proteínas animal diário que está inserido no contexto de outras populações da região Norte. Na Amazônia, o consumo do pescado é mais intenso em áreas distantes dos centros urbanos porque estão sujeitas a altos custos de transporte e de conservação (Gama et al., 2018).

\section{Considerações Finais}

A partir da pesquisa de campo, constatou-se que os produtores de açaí das comunidades Anapú, Caji e Meruú, pertencentes ao município de Igarapé-Miri (PA), preferem açaí do tipo preto em associação com farinha d'água. Em relação ao consumo de açaí com açúcar, poucos produtores, relataram ter esse hábito alimentar, uma vez que a maioria possuí predileção pelo consumo de açaí sem uso de açúcar e os que possuem esse costume decorre da influência de algum parente que reside no meio urbano e repassou essa prática.

No que concerne ao consumo de açaí, observa-se que quase a totalidade dos produtores de açaí e seus familiares consomem polpa de açaí tanto na safra quanto na entressafra, mesmo a produção do fruto apresentar uma redução drástica. No período da safra, os produtores consomem em média 7,46 litros de açaí grosso/dia, apresentando um consumo familiar per capita de 292,80 litros, enquanto que na entressafra o consumo médio é de 8,07 litros de açaí fino/dia e cerca 314,86 litros de consumo familiar per capita. Na entressafra diminui a qualidade para atender todos consumidores da familia adicionando mais água no açaí grosso.

Em relação a frequência de consumo de açaí, a maioria dos entrevistados, relataram ingerir polpa de açaí no almoço, no jantar e na merenda durante todos os dias da semana. Vale ressaltar que a merenda, geralmente, é constituída por mingau de farinha ou arroz com açaí durante o período da manhã, outro tipo de merenda consiste na ingestão do caroço de açaí previamente macerado acompanhado com farinha. Outro tipo é o chopp (sacolé, chope, etc) e picolé de açaí.

Os produtores de açaí, das três comunidades estudadas, possuem o hábito de consumirem a polpa de açaí em associação com algum alimento proteico. O consumo de mingau com açaí, como merenda, pela manhã não pode faltar, por que fornece energia para que consigam desenvolver suas atividades até o momento do almoço. Os principais alimentos proteicos que são ingeridos com açaí são peixe, camarão, charque, carne bovina, frango e porco, constituindo a dieta alimentar básica para os produtores de açaí, que além de obterem renda, o hábito diário de consumo de açaí está integrado ao longo do ano. 


\section{Referências}

Azevedo, J. R. de. (2005). Tipologia do sistema de manejo de açaizais nativos praticados pelos ribeirinhos em Belém, Estado do Pará. Dissertação (PósGraduação em Agriculturas Amazônicas) - Universidade Federal do Pará/Empresa Brasileira de Pesquisa Agropecuária, Belém.

Brasil. (2016). Ministério da Agricultura, Pecuária e Abastecimento. Gabinete do Ministro. Portaria n 58 , de 30 de agosto de 2016 . Regulamenta a fixação dos padrões de identidade e qualidade para polpa de açaí. Diário Oficial da União, Brasília, DF, 1 set. 2016. p.3.

Cedrim, P. C. A. S., Barros, E. M. A., \& Nascimento, T. G. do. (2018). Propriedades antioxidantes do açaí (Euterpe oleracea) na síndrome metabólica. Brazilian Journal of Food Technology, 21.

Embrapa. (2019). Anuário leite 2019. Embrapa.

Embrapa. (2018). Anuário leite 2018: indicadores, tendências e oportunidades para quem vive no setor leiteiro. Juiz de Fora, MG: Embrapa.

Bezerra, V. S., Silva, O. F., \& Damasceno, L. F. (2016). Açaí: produção de frutos, mercado e consumo. Jornada Científica, 2, 2016. Belém: Embrapa.

Carvalho, G. R., Rocha, D. T. \& da, Gomes, I. R. (2018). O mercado de leite em 2017.: Embrapa.

Freddo, A. R. L. F. (2018). Açaí. Companhia Nacional de Abastecimento. Boletim da Sociobiodiversidade, 2(4), Brasília: Conab.

Gama, A. S. M. 2018. Inquérito de saúde em comunidades ribeirinhas do Amazonas, Brasil. Caderno de Saúde Pública, 34 (2).

Gerhardt, T. E., \& Silveira, D. T. (2009). Métodos de pesquisa. Editora da UFRGS.

Guedes, Marcelino Carneiro et al. (2018). Calendário adaptado para monitoramento da produção de açaí. Macapá: Embrapa. (Comunicado técnico, n. 153)

Homma, A. K. O., Nogueira, O. L., Menezes, A. J. E. A. de, Carvalho, J. E. U. de, Nicoli, C. M. L., \& Matos, G. B. de. (2006). Açaí: novos desafios e tendências. Amazônia: ciência \& desenvolvimento, 1(2).

Idesp. (2011). Estatística municipal: Igarapé-Miri. SEPLAN.

Lakatos, E. M., \& Marconi, M. de A. (2010). Fundamentos da metodologia científica. Atlas.

Lakatos, E. M., \& Marconi, M. de A. (2004). Metodologia científica. (4a ed.), Atlas.

Mendes, A. M. et al. (2012). O mercado de açaí no estado do Pará: uma análise recente. Amazônia: ciência \& desenvolvimento, 8(15).

Menezes, A. H. N. et al. (2019). Metodologia científica teoria e aplicação na educação a distância. Petrolina: Universidade Federal do Vale do São Francisco.

Mourão, L. (2010). História e natureza: do açaí ao palmito. Revista Territórios e Fronteiras, 3(2).

Nogueira, O. L. et al. 2005. Açaí. Belém: Embrapa Amazônia Oriental.

Nogueira, O. L., \& Homma, A. K. (1998). Análise econômica de sistemas de manejo de açaizais nativos no estuário amazônico. Embrapa-CPATU.

Pepper, L. G., \& Alves, L. de F. N. (2016). O açaí ribeirinho certificado: uma forma de garantir o reconhecimento de um produto diferenciado e de assegurar renda duradoura para ribeirinhos do Estuário Amazônico. Cadernos de Agroecologia, 10 (3). http://revistas.abagroecologia.org.br/index.php.

Rocha, N. H., Bevilacqua, P. D., \& Barletto, M. (2015). Metodologias participativas e educação permanente na formação de agentes comunitários/as de saúde. Trabalho, Educação e Saúde, 13(3), 597-615.

Rojas, C. P. (2017). Relações do manejo do açaizeiro com as mudanças da vegetação e com a economia do estabelecimento familiar ribeirinho em várzeas na comunidade de Manoel Raimundo, Cametá, PA. Dissertação (Programa de Pós-Graduação em Agriculturas Amazônicas) - Universidade Federal do Pará/Empresa Brasileira de Pesquisa Agropecuária, Belém.

Santana, A. C. de, Santana, Á. L. de, \& Santana, Á. L. de. (2017). Açaí pulp demand in the retail market of Belém, State of Pará. Revista Brasileira de Fruticultura, 39(1).

Santana, A. C. de, Santana, Á. L. de, \& Santana, Á. L. de. (2014). Análise discriminante múltipla do mercado varejista de açaí em Belém do Pará. Revista Brasileira de Fruticultura, 36(3), 532- 541.

Silva, B. da, \& Amorim, T. S. (2017). A produção, venda e renda do açaí: um estudo no município de Igarapé-Miri /PA. Simpósio Internacional de Geografia Agrária, 8, 2017, Curitiba. Anais... SINGA.

Silva, C. N., Lima, R. S., Silva, J. P. da, Lima, R. Â. P. de, Vilhena, T. M., \& Monteiro, P. G. B. (2016). Estratégias de sobrevivência na Amazônia paraense: o caso dos moradores do baixo Rio Meruú (Igarapé-Miri/Pará/Brasil). Geosul, Florianópolis, 31(62), 173-191.

Silva, M. A. da, Aride, P. H. R., Santos, S. M. dos, Araújo, R. L., Lima, J. P., Braga, T. M. P., \& Oliveira, A. T. de. (2014). Preferências e restrições alimentares de moradores do município de Juruá, Amazonas. Scientia Amazonia, 3(3), 106-111.

Silva, M. G. (2018). Efeitos da dieta hipoenergética associada ao consumo de açaí (euterpe oleracea Mart) no estado antioxidante de indivíduos com excesso de massa corporal e dislipidemia. Dissertação (Mestrado em Medicina/Cardiologia) - Universidade Federal do Rio de Janeiro.

Silva, P. A. et al. (2013). Caracterização de farinhas de tapioca produzidas no estado do Pará. Ciência Rural, 43(1), $185-191$. 
Research, Society and Development, v. 10, n. 9, e51710918376, 2021

(CC BY 4.0) | ISSN 2525-3409 | DOI: http://dx.doi.org/10.33448/rsd-v10i9.18376

Vieira, A. H. et al. (2018). Cultivo do Açaizeiro (Euterpe oleracea Martius) no Noroeste do Brasil. Embrapa Rondônia.

Yamaguchi, K. K. L., Pereira, L. F. R., Lamarão, C. V., \& Lima, E. S. (2015). Amazon acai: Chemistry and biological activities: A review. In: Food Chemistry, 179, 137-151. 